\title{
Dynamic Seating in Learners with Down's Syndrome in South Africa
}

\author{
Lise Kathleen Reyneke, L K, BSc OT (UCT) M OT (SU), https://orcid.org/0000-0003-I 276-6030 \\ Occupational Therapist in Private Practice
}

*Munira Hoosain, BSc OT (UCT) M OT (SU), https://orcid.org/0000-000 I-5449-I43X

Lecturer, Division of Occupational Therapy, Faculty of Medicine and Health Sciences, Stellenbosch University

Introduction: The study aimed to investigate whether the classroom behaviour and task performance of learners with Down syndrome improved with the use of a stability ball as a classroom chair.

Method: A single-subject withdrawal design was utilised. There were three participants, aged ten to twelve, with Down syndrome in a special education classroom. Five phases of three weeks each were implemented alternately. Two phases incorporated usual classroom chairs and the other three phases made use of stability balls as chairs. Momentary time sampling was used to record learners' classroom behaviours in relation to their in-seat and on-task performance.

Results: A substantial positive change was found in the learners' on-task performance when seated on stability balls instead of chairs. Results differed across participants; with some demonstrating a definite difference in the usual daily average on-task performance, while others showed steadier patterns of on-task behaviour in comparison with their usual fluctuating levels of attention.

Conclusion: Stability ball seating is a non-invasive intervention strategy that can be effectively utilised in classrooms and occupational therapy clinical settings, to improve on-task behaviour in learners with Down syndrome.

Key words: Dynamic seating, Down syndrome, attention, in-seat behaviour, on-task behaviour

\section{INTRODUCTION}

Attention difficulty and related disruptive behaviours in the classroom' are frequently experienced by educators in mainstream and special education classes alike. There are limited non-pharmacological management strategies that can be implemented in these settings. Disruptive behaviours are mostly associated with Attention Deficit Hyperactivity Disorder (ADHD). However, they are also evident in children with Down syndrome (DS) and other diagnoses $^{2-4}$.

Down syndrome, first described in 1866, manifests as learning difficulties, cognitive impairment and specific physical characteristics $^{5}$. Children with DS present with generalised low muscle tone and an unstable postural control, which together results in poorlydeveloped motor function ${ }^{6}$. There is general consensus that learners with DS are more prone to attention deficits than their peers ${ }^{5}$.

Adapting classroom environments may be an effective nonpharmacological strategy to address problematic classroom behaviours $^{7-14}$. Since 2003, researchers have investigated whether using stability balls instead of usual chairs in classrooms can enhance learners' attention ${ }^{7-14}$, by minimising disruptive behaviours. The evidence base on dynamic seating has been consistently growing. Researchers in the field, of whom the majority have been occupational therapists ${ }^{8-11,13-17}$, have proposed it as a pragmatic classroom strategy to use with all learners experiencing attention difficulties. Existing research has been conducted in mainstream, inclusive and special education classrooms, mostly in urban areas of the United States of America (USA). To date, research has focused mainly on learners with $A D H D^{8,12,16}$ and Autism Spectrum Disorder (ASD) $)^{9,13,17}$. Current research indicates positive results, with suggestions that future research investigates the long-term ${ }^{11,16}$ effect of dynamic seating on learners' behaviours in classrooms.

Various dynamic seating options are available, including stability balls, standing desks, rocking chairs and inflatable cushions. Most studies have focused on stability balls, with limited studies investigating other options. Stability balls ${ }^{10,11}$ are also referred to as therapy balls ${ }^{8,9}$, Swiss balls ${ }^{18}$, or exercise balls ${ }^{13}$. These inflatable rubber balls, ranging in size from $35 \mathrm{~cm}$ to $120 \mathrm{~cm}$, are used in various settings, e.g. gymnasiums, Pilates classes, occupational therapy and physiotherapy practices, offices, and for different purposes, e.g. creating balance challenges, performing strengthening exercises, or improving sitting posture ${ }^{18}$.

Optimal Stimulation Theory (OST) and Sensory Integration (SI) are two main schools of thought found to explain the effects of dynamic seating on behaviour. They agree that sensory information can influence behaviour and attention ${ }^{19,20}$, and that sensory seeking behaviours are more often seen in learners with $A D H D^{21,22}$. The theories differ in that OST assumes that all learners will benefit from the addition of a novel element ${ }^{12}$, while SI theorists propose that the efficacy of a dynamic seating strategy depends on the learner's particular sensory processing profile ${ }^{13}$. Another fundamental difference is the classification of environmental stimulation; on whether certain inputs hinder or support attention. For example, background noise may be considered a distraction in an SI framework, but OST researchers consider this type of auditory input as promoting positive classroom behaviours ${ }^{23,24}$. OST takes the view that learners with attention difficulties will react to non-stimulating environments in similar and equal ways than typically developing learners would react to overstimulating environments ${ }^{21}$.

Movement integration (MI) is a third interpretation of the benefits of dynamic seating ${ }^{23}$, but this is conceptualised more as an intervention than a theoretical construct. It makes the assumption that movement has educational benefits ${ }^{25}$ and as such should form an integral and essential part of a learner's school day.

Movement is key to a learner's academic potential and performance ${ }^{25,26}$, and so, to a large extent, the success of a dynamic seating strategy is determined by how much movement it instigates and allows. These do not only have to be large, noticeable movements ${ }^{25,27}$. Sitting on a stability ball requires adequate neural feedback to detect the balance requirements, activation of the core muscles, alertness, and responsiveness to changing balance demands ${ }^{17}$. It also allows the learner opportunities for movements such as gentle bouncing or rocking. Moreover, the inherent balance demand of a therapy 


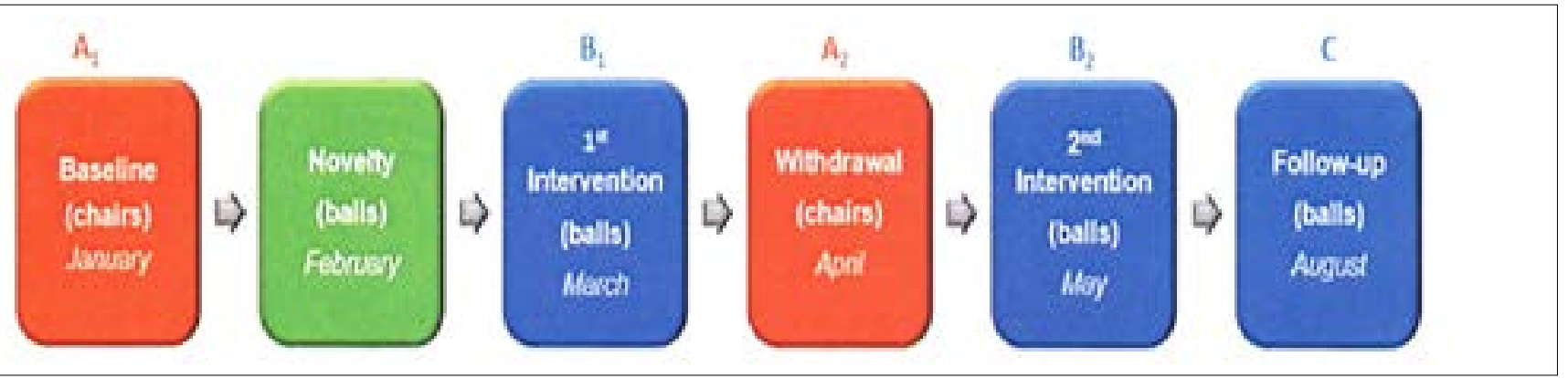

Figure I: Research Phases

ball means that the learner normally should use at least one limb ${ }^{17}$ in a supportive manner. The muscle activation required to maintain the upright posture when seated on the ball, assists the learner in remaining receptive to environmental inputs and reaching an optimal state of arousal ${ }^{8,26}$. In this way, on-task performance is improved, and disruptive behaviours are minimised ${ }^{12}$.

In-seat and on-task performance are the most commonly used variables to record the effectiveness of dynamic seating ${ }^{7-11,13,14}$. Data collection is through behaviour recording while observing activity, and is used to determine the regularity and frequency of a specific behaviour ${ }^{28,29}$. Participants are observed for a pre-determined time segment, e.g. 20 minutes, and the time segments are broken up into smaller intervals, e.g. I 0 seconds. Each individual participant's percentages per session are then presented in a linear graph for visual analysis. There was no evidence that any previous studies have done statistical analyses on this data set. Only two studies published in $2012^{14}$ and $2015^{11}$ respectively, explored alternative seating using randomised controlled trials (RCT). These studies utilised computerised data collection in order to obtain measures of effect that were not reliant on the opinion of an observer.

Single-subject (SS) withdrawal designs or time-series designs are typically the design of choice in special education research pertaining to dynamic seating ${ }^{8-17}$. In this design, the participant serves as their own control ${ }^{27}$, and data is recorded and reported for each individual participant during different phases where an intervention is alternately applied and withdrawn. This use of different phases is an integral part of SS research ${ }^{30}$ in order to determine baseline behaviour and compare it to experimental phases. The use of two experimental and two control phases helps to strengthen the association between variables ${ }^{28,31}$.

Three studies ${ }^{8-10}$, conducted in USA, used withdrawal design to explore the difference in time learners spent in their seats when seated on stability balls rather than classroom chairs. Visual analysis of all three studies revealed that learners spent a noticeably larger percentage of the time in-seat during ball phases. Researchers also noted decreases in disruptive and oppositional behaviour for some of the participants. All three ${ }^{8-10}$ concluded that sitting on a ball could positively affect learners' classroom behaviours. A fourth study, conducted with six male learners with ASD at a public school in Los Angeles, reported mixed results ${ }^{13}$ of the stability balls on the learners' in-seat behaviour. The researchers concluded that the effect of stability ball seats was related to sensory processing patterns. A more pronounced effect was seen in learners with vestibularproprioceptive seeking behaviours.

Of the three studies investigating on-task performance, two found that seating learners on balls had a positive effect ${ }^{9,10}$ on the amount of time learners spent on-task. Schilling et $\mathrm{al}^{9}$, observed four learners with ASD. Visual analysis of the individual graphs illustrated substantial improvement ${ }^{9}$ in each participant's on-task behaviour. On-task performance immediately declined upon withdrawal, strengthening the association between the intervention and the observed behaviours. Fedewa and Erwin ${ }^{10}$, combined the observational data from eight participants measured over twelve weeks, and found a substantial and cumulative increase, from $10 \%$ in the first week to $80 \%$ in the last week, in the group's average on-task performance. In contrast, Bagatell et al 13:900 stated "the use of the therapy ball chair did not positively affect engagement" It is possible that use of a stability ring in this study changed the fundamental properties of ball seating that usually elicit the observed phenomenon.

Without exception, researchers conducting SS research in the field of dynamic seating recommended replication of studies because the sample sizes were small and could not be generalised to the general population. There were no available studies on dynamic seating with learners in South Africa, or with any learners with DS.

The aim of this study was to examine the short- and long-term impact of stability ball seating on classroom behaviours in learners with DS in South Africa.

\section{METHOD}

\section{Research design}

A quantitative, quasi-experimental study using a SS withdrawal design in the natural classroom setting was utilised. Participants received the intervention in an A-B-A-B-C design ${ }^{32}$. A diagrammatic representation of the process followed is presented indicating the relevant seating conditions for each phase. See Figure $I$ above.

$A$ indicates the baseline and withdrawal phases where learners were seated on chairs; $B$ indicates the first and second intervention phases where learners were seated on balls. A novelty period followed the baseline data collection to allow the learners' habituation to the balls and eliminate the recording of any novelty effects during the first intervention phase. Follow-up (C) was completed during the third term of the school year in which the study took place to determine whether the effect of the balls on classroom attention, if any, persisted beyond the initial phases.

\section{Study population}

The study population comprised learners with DS attending Learners with Special Educational Needs (LSEN) unit in the Western Cape of South Africa.

\section{Sampling}

Convenience sampling was used to select the LSEN unit at a mainstream school in Malmesbury, a small town about 70km from Cape Town. The unit accommodates twelve learners with a variety of diagnoses, including DS, hearing impairment, ASD, cognitive impairment, and cerebral palsy. The three learners with DS in the LSEN unit participated in the study following receipt of informed consent from the three families. These three learners were aged ten to twelve years.

The inclusion criteria were: diagnosis of DS, regular attendance of LSEN unit as specified by Western Cape Education Department (WCED) regulations. Exclusion criteria were: learners with balance/ equilibrium issues, postural control deficits placing them at high risk of falling or additional diagnoses such as ASD or CP.

All three learners with DS met the inclusion criteria and consented to participating in the study. Parents also consented and completed the required questionnaires. Participants were all mixed-race and from similar lower-middle income areas, but differed widely in co-morbid diagnoses, level of function and skill. All three learners had joined the LSEN unit in the year they were due to start grade $\mathrm{I}$. 


\section{Data collection}

Direct classroom observation commenced the second week of the first school term and the first four phases were completed by the end of the second term. The learners continued to sit on balls upon completion of phase $B_{2}$, and follow-up commenced during the third term. All phases lasted three weeks each, except for the novelty phase, which lasted two weeks. The follow-up phase could not be conducted at the very end of the school year, as the WCED prohibits research in schools during the fourth term due to examinations.

Data collection included ( $\mathrm{I}$ ) a questionnaire for parents, and (2) direct observation of participants in their classroom.

\section{Questionnaire for parents}

Parents of each learner completed a questionnaire detailing the learner's medical, socio-emotional and behavioural information, as well as current occupational performance at home, at school and in the community. This provided background information of the participants' contexts.

\section{Direct classroom observation}

Monday to Thursday mornings from 8:30 - 9:15 was the dedicated time where the learners were simultaneously engaged in desktop activities. This proved to be the most suitable time for observation of the participants. The participants sat on the stability balls for the entire 45-minute time period, and data were recorded twice weekly during the middle 30 -minutes to allow for late start and early completion ${ }^{8,9}$.

The following classroom behaviours were established as dependent variables to be measured during direct observation, with definitions adapted for this study ${ }^{8,9,17,33}$ : In-seat (chair/ball), Outof-seat, On-task and Off-task.

Frequent, repetitive measurements ${ }^{34}$ across all phases of a SS withdrawal design are essential. Ten-second interval recording was selected for this study. This is because it is described as more sensitive and reliable than continuous recording ${ }^{33}$.

Learners remained at their usual place at their tables, regardless of whether they were seated on chairs or balls. The researcher used a stopwatch to look up at a participant every ten seconds. The behaviour observed at that exact moment was coded on the form as in-seat (x) or out-of-seat (o), and as on-task (x) or off-task (o).

The order in which participants were observed was predetermined and randomised to ensure an equal chance of being observed during the beginning, middle and later stages of each session across phases.

\section{Data management}

Data forms were labelled with pseudonyms and the data collection date. The calculated percentages of in-seat and on-task behaviours for each session were captured on an Excel spreadsheet.

Results from SS studies are usually visually analysed ${ }^{31}$. The data were converted into graphs to provide a visual representation of classroom behaviours. Each phase was represented in two graphs, illustrating in-seat and on-task behaviours separately. The five graphs for each behavioural variable were placed linearly for visual inspection.

\section{Data analysis}

Linear graphical representations were inspected for changes in variability $^{32}$, level ${ }^{32}$, latency ${ }^{30,31}$ and trends ${ }^{32}$ to contrast the behaviours seen when seated on stability balls versus chairs. This contrast allows analysis of the intervention's effect on behaviour.

\section{Internal validity}

Graphs were stringently analysed to avoid a demonstration of non-effect. The influence of any external variables were carefully considered upon analysis, especially with regards to latency ${ }^{30,31}$ and pre-existing trends ${ }^{32}$ observable during baseline.

Replication of phases is of key importance to enhance internal validity of SS research ${ }^{28}$. Data from SS studies should show at least three demonstrations of effect during intervention to be considered as evidence of effect ${ }^{28}$. The use of five phases in an $A B A B C$ design in this study would be adequate in attaining this requirement.

\section{Reliability}

The user was familiar with the application of the data-collection form as it was implemented in occupational therapy practice. The resultant expertise in using the form negated the need for a pilot study. Definitions of dependent variables were clarified to include all possible behaviours and thus allow the researcher to make instantaneous decisions on how to code observed behaviours. The first author was the only observer and rater during this study, thus inter-rater reliability was not established for this study.

\section{Ethics}

Ethics approval was obtained from the Human Research Ethical Committee (HREC) at Stellenbosch University (SI 3/ I I/228). Permission to approach the learners was also granted from the WCED.

\section{RESULTS}

No objections were encountered upon the introduction or removal of the stability balls during the different phases, and all three participants completed the five phases of the $A B A B C$ design in entirety. No learners withdrew from the study. Participant I was II years old, Participant 2 aged 12 years, and Participant 3 was ten years old at the time of the study.

\section{In-Seat performance}

Allowances could not be made for the time learners had to spend out-of-seat to retrieve tasks during their perceptual-motor time slots. The obtained data sets on in-seat and out-of-seat behaviours were therefore not meaningful, as they included instances of out-ofseat behaviours that were actually on-task. Therefore, this variable was not included in the analysis.

\section{On-task performance: Participant I}

Depending on the phase of the study, Participant I required occasional verbal cues from his educator to remind him whether to sit on a stability ball or a chair. The dotted lines in Figure 2 (see page 23) indicate Participant I's mean on-task performance for each phase in its entirety. The phase averages for the respective sessions were $69 \%$, $99 \%, 75 \%$, $88 \%$ and $90 \%$.

\section{Changes in variability}

A distinct change was seen in the variability of data following the introduction of stability balls during the second phase $\left(B_{2}\right)$. The close proximity of data points suggested increased stability and steadiness of on-task performance whilst seated on a ball. Subsequent withdrawal of the intervention during the third phase $\left(A_{2}\right)$ exemplified a return to day-to-day variability in on-task performance. On-task performance showed a recurrent levelling in variability upon the second introduction of balls $\left(B_{2}\right)$. However, this change in variability was not as pronounced as during the first intervention.

The follow-up (C) phase illustrated data with variability that was similar to the second intervention phase, with all scores falling between $80 \%$ and $100 \%$. A particularly low percentage on-task performance was seen during the fifth session of the follow-up phase. Normal seating arrangements were not adhered to during this session, as the learners at Participant I's table were joined by an I I-year old learner with cerebral palsy. This learner was usually seated in her buggy at a different table with one other learner to minimise distractions from the other learners. This was because she was known to be restless and uncooperative during perceptualmotor sessions.

\section{Changes in level}

The changes evident in the level of data for each phase suggest a change in the mean percentage of on-task performance depending on whether Participant I was seated on a chair or stability ball. The calculated means of on-task performance indicate an escalation of average on-task performance during each intervention phase, and a 


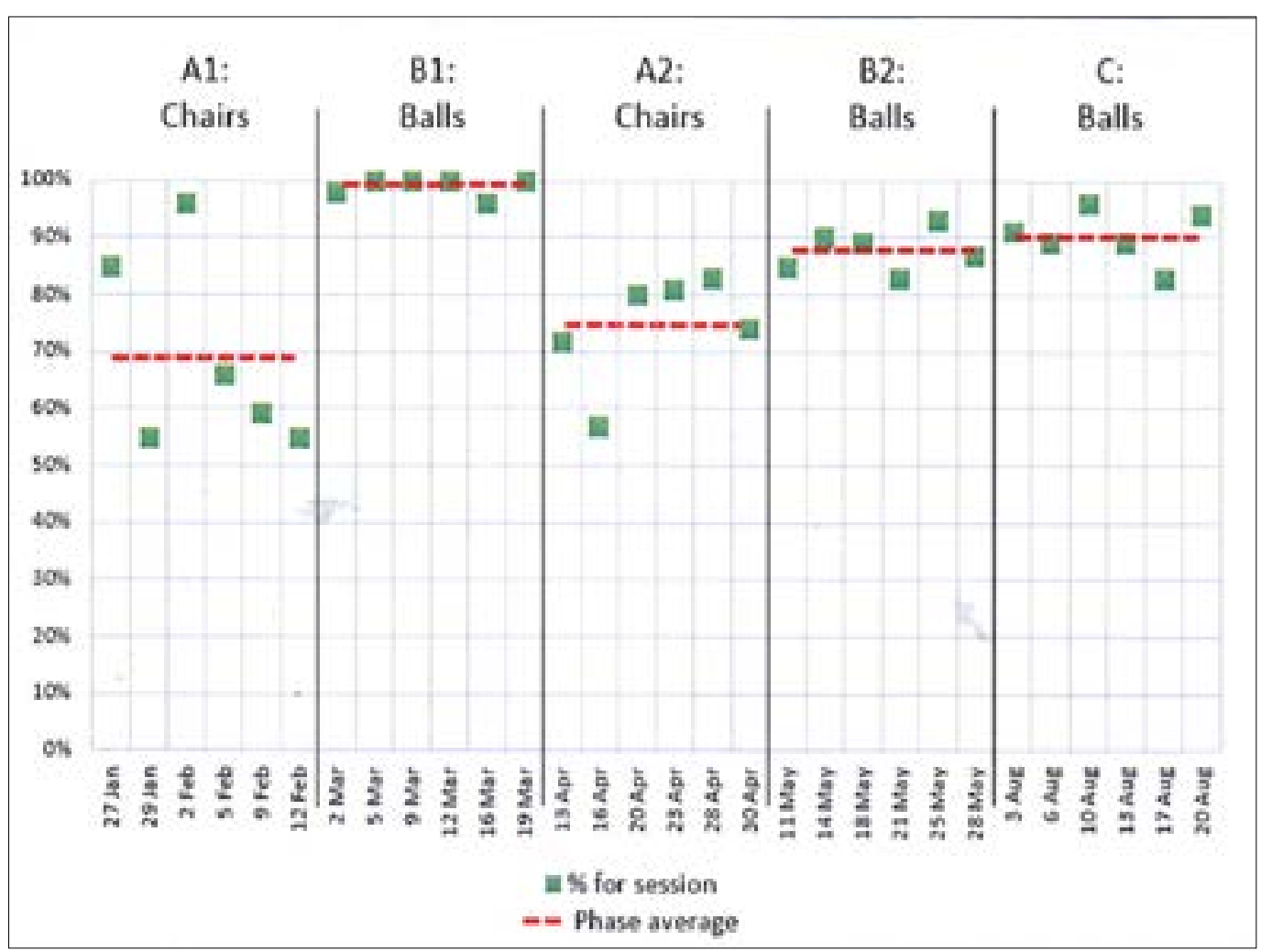

Figure 2: Participant I's on-task performance per session

reduction during each withdrawal phase. Although the mean on-task performance was somewhat lower during the second intervention and follow-up phases, it remained consistently higher than baseline scores. Performance percentage remained higher than baseline on withdrawal, suggesting a residual effect.

\section{Trends}

Upward or downward trends were not observable in the distribution of data, neither per phase nor throughout the entire data collection period.

\section{Other comparisons}

The possible influence of the intervention on classroom behaviour was further explored by tallying results from the two chair $\left(A_{1}\right.$ and $\left.A_{2}\right)$ and the three ball $\left(B_{1}, B_{2}\right.$ and $\left.C\right)$ phases into combined scores for each respective seating condition, as displayed in Table I below.

The ball phase's mode score suggests that Participant I could typically sustain his attention for the full observation session while seated on a stability ball. This positive effect was supported by the higher mean and median scores during stability ball seating. Participant I's highest scores were similar during ball and chair phases, but there was a $28 \%$ difference between the lowest scores in each phase. This suggests that even on days when Participant I's attention was poor, his on-task behaviour was typically better while seated on a ball.
No particular reason was noted for Participant I's atypically highest chair conditions' score of $96 \%$.

On-task performance: Participant 2

Participant 2 expressed pleasure at receiving a pink ball, and always gave full cooperation when requested to sit on the ball during intervention phases. Her on-task performance data and phase averages are graphically illustrated in Figure 3 (see page 24).

\section{Changes in variability}

Similarly to Participant I, the on-task data from Participant 2's observations showed changes in the variability of data across the phases: stabilisation when seated on a ball, and increased irregularity when seated on a chair. As shown in Figure 3 (page24).

\section{Changes in level}

Participant 2's mean on-task performance increased by $14 \%$ from the first $\left(A_{1}\right)$ to the second $\left(B_{1}\right)$ phase. The phase average lines were consistently higher during the ball phases, indicating an improved usual on-task performance during the intervention $\left(B_{1}\right.$ and $\left.B_{2}\right)$ phases. The graphs also showed a decline in mean on-task performance upon return to baseline.

\section{Trends}

No simple linear trends were observable in the distribution of data per phase. The mean on-task percentage decreased with subsequent intervention phases, from $98 \%$ to $95 \%$ to $94 \%$. However, Participant 2 and Participant I were always seated at the same table. Therefore, she also experienced the same level of distraction during the fifth observation session of the follow-up phase, when the learner with cerebral palsy joined their table. The much lower score of $81 \%$ on-task for that particular session subsequently reduced her mean on-task performance score for the phase. The effect of the ball seemed to lessen over time as the learner habituated. However, an inference could not be accurately made in terms of the effect of the ball on the learner due to the variable properties of another learner joining the table.

\section{Other comparisons}

The contrast of the mean, median and mode scores in Table I below indicated overall improved on-task behaviour while seated on a ball.

Table I: Comparison of mean, median, mode, upper and lower scores

\begin{tabular}{|c|c|c|c|c|c|c|}
\hline & \multicolumn{2}{|c|}{ PARTICIPANT I } & \multicolumn{2}{|c|}{ PARTICIPANT 2} & \multicolumn{2}{|c|}{ PARTICIPANT 3} \\
\hline & $\begin{array}{c}\text { CHAIR } \\
\text { CONDITIONS }\end{array}$ & $\begin{array}{c}\text { BALL } \\
\text { CONDITIONS }\end{array}$ & $\begin{array}{c}\text { CHAIR } \\
\text { CONDITIONS }\end{array}$ & $\begin{array}{c}\text { BALL } \\
\text { CONDITIONS }\end{array}$ & $\begin{array}{c}\text { CHAIR } \\
\text { CONDITIONS }\end{array}$ & $\begin{array}{c}\text { BALL } \\
\text { CONDITIONS }\end{array}$ \\
\hline MEAN & 72 & 92 & 83 & 96 & 62 & 87 \\
\hline MEDIAN & 73 & 92 & 84 & 96 & 61 & 89 \\
\hline MODE & 55 & 100 & 83 & 100 & 48 & 89 \\
\hline HIGHEST SCORE & 96 & 100 & 96 & 100 & 85 & 98 \\
\hline LOWEST SCORE & 55 & 83 & 59 & 81 & 26 & 67 \\
\hline
\end{tabular}




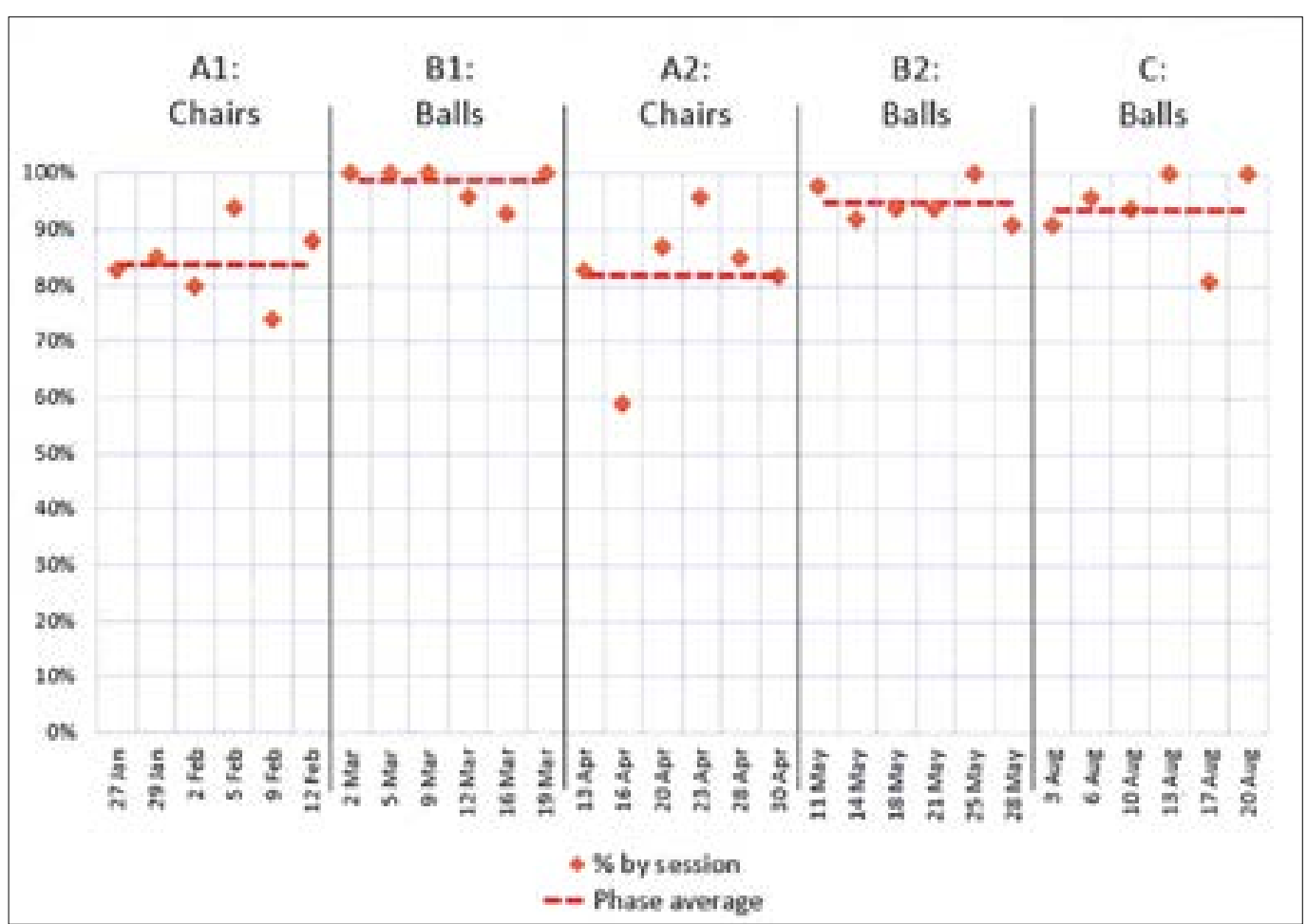

Figure 3: Participant 2's on-task performance per session

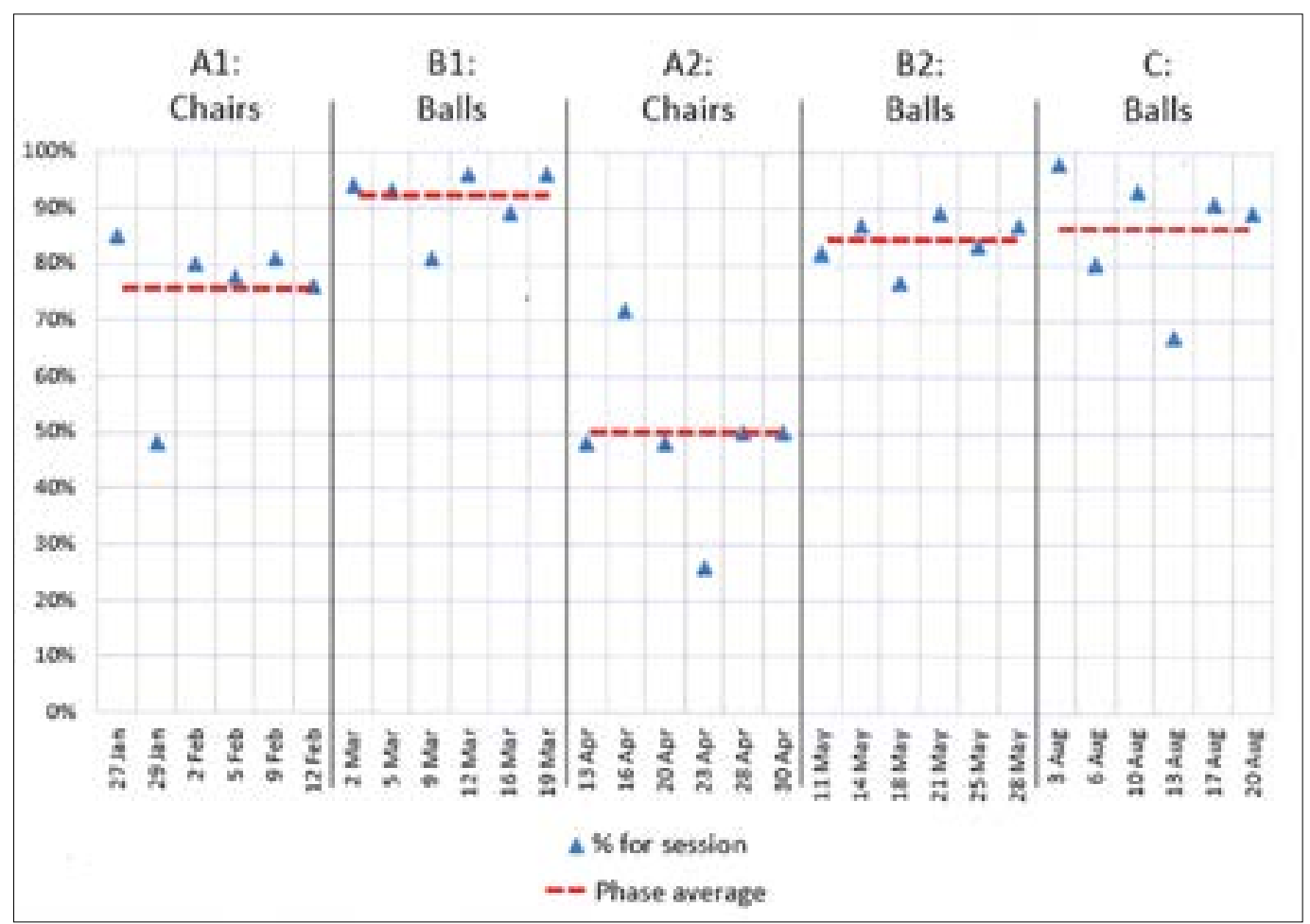

Figure 4: Participant 3's on-task performance per session

\section{On-task performance: Participant 3}

Participant 3 occasionally forgot that he had to sit on the ball during perceptual-motor time. The educator would remind him that they were currently sitting on balls when she saw that he was on a chair. Attention was drawn to Participant I and Participant 2 on the balls as a visual cue. A verbal request that he exchange his chair for his ball resulted in him willingly doing so. Figure 4 above graphically represents Participant 3's on-task performance and phase averages.

Participant 3's phase averages indicate a typically lower baseline than the other two participants. However, during the intervention phases, he performed similarly to Participant I and Participant 2 by maintaining a phase mean of above $80 \%$ in all ball phases.
Changes in Variability

Participant 3's data continued to fluctuate throughout all the phases, indicating that the ball did not have a stabilising effect on his on-task performance. Although less variability was found during the initial intervention phase $\left(B_{1}\right)$, this effect tapered in subsequent intervention phases, especially in follow-up. The high level of variability was in keeping with the collateral information from parents and educators indicating that Participant 3 did not always give full cooperation during task time in class, often choosing to leave his task in preference of a toy.

Interestingly, the learner who changed seats and caused a drop in on-task performance for Participant I and Participant 2 , was usually seated at a table with Participant 3. Participant 3 had a high $91 \%$ on-task performance score for this session, when not seated with this particular learner.

\section{Changes in Level}

Despite continued variability, a definite positive change in level could be seen during all the intervention phases. The dotted lines in Figure 4 (on the left) clearly show higher and lower averages of on-task performance depending on the seating conditions.

\section{Trends}

No visible trends were apparent during the individual phases. However, the effect of the ball on variability of on-task behaviour lessened over time. This is represented by the difference between Participant 3's highest and lowest scores from the first intervention phase to the last. Whilst the differences between on-task performance of the first and second intervention phases were comparable, the difference between on-task performance for his best day and his worst day was close to double during the follow-up phase. Similar trends were not noted in the other two participants, as seen in Table II below.

Table II: Difference in Participant 3's upper and lower scores during intervention phases

\begin{tabular}{|l|c|c|c|}
\hline & B I & B2 & C \\
\hline HIGHEST ON-TASK \% & 96 & 89 & 98 \\
\hline LOWEST ON-TASK \% & 81 & 77 & 67 \\
\hline DIFFERENCE & 15 & 12 & 31 \\
\hline
\end{tabular}




\section{Other comparisons}

Participant 3's mean and median scores show that on-task behaviour was consistently improved during ball phases. Like Participant 2, Participant 3's lowest score during any ball phase was also higher than the lowest score he achieved during any chair phase, although the difference in his scores was more pronounced.

The mode of $89 \%$ during ball conditions was achieved only three times during the intervention phases and was therefore not considered an accurate reflection of typical behaviour. Instead, the highest and lowest scores under different conditions were considered for evidence of effect. A higher range of scores was achieved during ball conditions $(67 \%-98 \%)$ than chair conditions (26\% - 85\%); and the lowest ball score $(67 \%)$ was closer to the highest chair score $(85 \%)$ than to the lowest chair score $(26 \%)$. These observations confirmed that the intervention had a positive effect on Participant 3's on-task behaviour.

\section{Latency periods}

No periods of latency were observable after introduction or withdrawal of the intervention; all positive and negative effects were immediate for all three participants.

\section{Incidental Findings}

After data collection, the educator reported that she had purposefully not corrected learners' seated posture during the ball phases as she did not want to interfere with the research process. However, during the chair phases she continued to give customary verbal and tactile reminders to learners to maintain good seated posture. Despite the lack of postural reminders during intervention phases, ball seating still improved classroom behaviours.

\section{DISCUSSION AND IMPLICATIONS OF THE RESEARCH}

This study addressed recommendations and questions from previous research regarding systematic replication with different populations to enlarge the evidence base, and long-term effects of using stability seating. It was the first study in the field done with learners with DS, and the first of its kind in South Africa.

Results from this study are in agreement with other literature in the field in several ways: the intervention was positively received $^{8-10}$ by learners and educators; stability ball seating had a positive influence on learners' engagement-on-task ${ }^{8-10,14}$ in the short-term; and greater benefit was seen in the participant with the lower baseline ${ }^{10}$.

Similarly to related research ${ }^{11,25}$, this study considered movement to be the key aspect in changing learners' behaviour, making it an ideal MI strategy to introduce in special education classrooms. The concept of adding movement elements to enhance attentional ability ${ }^{12}$ was consistent with Zentall's Optimal Stimulation theory ${ }^{20,22}$.

Visual analysis of the in-seat linear graphs led to the conclusion that any changes in variability, level, trend and latency were arbitrary and incidental, due to the inherent requirements of the perceptualmotor session where learners had to get up to collect and store activities. Similar situations were encountered in other studies ${ }^{8,9}$.

Improvements seen during the intervention were not consistent across participants. In keeping with previous research $\mathrm{h}^{1,9}$, learners with lower baselines benefitted more from stability ball seating. It was also noteworthy that the first intervention phase appeared to have the most prominent effect for each of the participants. While the latter intervention phases still exhibited an immediate and substantial improvement to behaviour, the effects were less pronounced. These particular effects were not reported in previous research ${ }^{8,9}$. In fact, some other studies noted a consistent, cumulative increase in positive classroom behaviours throughout the study period ${ }^{10}$. However, all of these studies $^{8-11}$ recommended follow-up over longer terms to further explore habituation and cumulative effects.

\section{Classroom seating considerations}

The classroom seating plan is a confounding factor, as clearly shown during the fifth session in the follow-up phase, where a disruptive learner moved from Participant 3's table to Participant 2 and Participant I's table. Inclusive education ${ }^{35}$ requires that learners receive every possible support and adaptation so that they may learn optimally. Moving this disruptive learner to a table of her own would not only improve Participant 3's attention, but most likely also her own as she will have less opportunity for off-task behaviour.

The intervention occurred during the morning perceptual-motor session. Further investigation is needed to determine whether a stability ball seat would have similar effects on classroom behaviour during other times, e.g. during interactive whiteboard activities, story time, or later during the school day.

\section{Residual effect}

This study did not utilise washout phases to eliminate residual effects upon return to baseline. While this addition may have strengthened the association between variables, it undermines the objective of establishing the effect of stability balls when used as a permanent or semi-permanent classroom seating strategy. Any residual effects were considered a further advantage of the stability ball strategy, as it was beneficial to the learners even when not in use.

Graphical data from previous research in the field ${ }^{8-10,14}$ consistently demonstrated a conspicuous and immediate decline in performance upon withdrawal of the intervention. The drop in performance upon withdrawal of the intervention not only suggests that there is no residual effect, but also strengthens the probability that the change noted in behaviour is a direct result of the intervention. Results from the current study confirmed that removal of the ball resulted in immediate decline of on-task performance ${ }^{8-11,14}$.

\section{Optimal state of arousal}

The belief is widely held by educators and parents alike that when learners are not fidgeting or moving, they must be maintaining sufficient attention levels. In previous studies, educators reported that learners appeared to be moving more ${ }^{8-10}$ while sitting on the stability balls, and the same was true for the current study. Yet results consistently indicated positive results on attention-to-task. The research base thus challenges the traditional notion that moving while working will distract a learner. All persons working with learners, especially learners with attention difficulties, should be encouraging movement. The study therefore provides evidence of the benefit of movement and dynamic seating in schools.

\section{Rigour}

The use of five phases in this study design resulted in four demonstrations of effect namely; all three participants showed an immediate improvement during the first intervention phase, participants' on-task performance decreased noticeably as soon as they went back to sitting on chairs, improvement was again seen when the intervention was introduced for the second time, and lastly during the follow-up phase. The addition of a follow-up phase in this study also began to provide evidence of long-term effectiveness ${ }^{8}$ and habituation ${ }^{10}$.

The study could have been strengthened by an independent observer and coder who was blinded to the study hypothesis. Reliability assessment of the data collection form would further have strengthened the study.

Educators may have influenced the findings through their atypical behaviour of not providing verbal reminders to the learners to correct seated posture. It seems unlikely that the lack of reminders may have improved learners' performance, but it is possible that the effect size was smaller than it would have been if educators had carried out their reminders as usual.

\section{Implications for practice}

Stability ball seating offers an evidence-based option to address problematic classroom behaviours before referral to a medical specialist and pharmacological intervention is considered. The 
strategy is also useful for occupational therapists in clinical practice. Occupational therapists typically use movement before and during activities to maintain arousal levels, and the ball offers another option for continued movement inputs. If the learner is at an optimal state of arousal throughout the therapy session, he/she will reap maximum benefit from the other therapeutic techniques.

This is the only South African study on ball seating to date. The participants enjoyed the stability balls and were happy to use them for chairs instead of toys, but the assumption cannot be made that the same will be true in isiXhosa, seSotho or isiZulu communities. Replication of the research in other South African communities is indicated.

\section{CONCLUSION}

Dynamic ball seating positively impacted the on-task behaviour of learners with DS in an LSEN classroom. Improvements in behaviour were evident for all three participants of this study when sitting on stability balls rather than traditional classroom chairs.

Stability ball seating is an ideal mechanism for movement integration in special education classrooms. Rocking, bouncing, or moving in any safe manner should not be discouraged, as it allows for self-regulation. Different dynamic seating practices (e.g. time spent on the ball, time of day, long-term use) need to be trialled in order to establish ideal protocols.

Seating on stability balls can also be used by therapists in clinical settings to improve on-task behavior and maintain arousal levels by providing continued movement input.

All participants and educators had positive attitudes towards stability ball seating in the classroom in this community. Social validity in other South African cultures and settings has not yet been established.

\section{CONFLICT OF INTEREST STATEMENT}

The authors declare that they have no conflict of interest. No funding was obtained for this study.

\section{REFERENCES}

I. Kercood S, Zentall S, Vinh M, Tom-Wright K. Attentional cueing in math word problems for girls at-risk for ADHD and their peers in general education settings. Contemporary Educational Psychology. 20I2; 37(2): $106-1 \mid 2$. https://doi.org/10.1016/j.cedpsych.2012.02.00।

2. Rice LJ, Gray K M, Howlin P, Taffe J, Tonge B J, Einfeld S L. The developmental trajectory of disruptive behaviour in Down syndrome, fragile $X$ syndrome, Prader-Willi syndrome and Williams syndrome. American Journal of Medical Genetics Part C: Seminars in Medical Genetics. 2015; (2): 182-187.

https://doi.org/10.1002/ajmg.c.31442

3. Chandler S, Howlin P, Simonoff E, O'Sullivan T, Tseng E, Kennedy J, et al. Emotional and behavioural problems in young children with autism spectrum disorder. Developmental Medicine and Child Neurology. 2016; 58(2): 202-208.

https://doi.org/10.1 I I I/dmcn. 12830

4. Koren G. Pharmacological treatment of disruptive behaviour in children with Fetal Alchol Spectrum disorder. Pediatric Drugs. 20I5; 17(3): 179-184 https://doi.org/10.1007/s40272-015-01 I8-4

5. Grieco J, Pulsifer M, Seligsohn K, Skotko B, Schwartz A. Down syndrome: Cognitive and behavioural functioning across the lifespan. American Journal of Medical Genetics Part C: Seminars in Medical Genetics. 2015; 169(2): 135-149.

https://doi.org//0.1002/ajmg.c.3 |439

6. Galli M, Rigoldi C, Mainardi L, Tenore N, Onorati P, Albertini G. Postural control in patients with Down syndrome. Disability \& Rehabilitation [serial online]. 2008 [2013 Jul 6]; 30(I7): I274-। 278. https://doi.org//0.1080/096382807016/0353

7. Martínez M, Duran X, Navarro J. Attention deficit disorder with or without hyperactivity or impulsivity in children with Down's syndrome. International Medical Review on Down Syndrome [serial online]. 20II [2013 Aug I7]; I5(2): I8-22.
http://doi.org/I0.1016/S2I7I-9748(II)70006-X

8. Schilling DL, Washington K, Billingsley FF, Deitz J. Classroom seating for children with attention deficit hyperactivity disorder: Therapy balls versus chairs. The American Journal of Occupational Therapy. 2003;57(5): 534-54I.

https://doi.org//0.5014/ajot.57.5.534

9. Schilling DL, Schwartz IS. Alternative seating for young children with autism spectrum disorder: Effects on classroom behavior. Journal of Autism and Developmental Disorders [serial online]. 2004 [2013 Jun 26]; 34(4): 423-432. https://doi.org// 0.1023/B:JADD.0000037418.48587.f4

10. Fedewa A L, Erwin H E. Stability balls and students with attention and hyperactivity concerns: Implications for on-task and in-seat behaviour. The American Journal of Occupational Therapy. 201 I; 65(4): 393-399. https://doi.org/I0.50I4/ajot.20II .000554

I I. Fedewa A L, Davis MA C, Ahn S. Effects of stability balls on children's on-task behaviour, academic achievement, and discipline referrals: a randomized controlled trial. American Journal of Occupational Therapy [serial online]. 2015 [Feb 3, 20I6]; 69(2): Feb 3, 2016. https://dx.doi.org/I0.50I4/ajot.2015.014829

12. Kercood S, Banda D R. The effects of added physical activity on performance during a listening comprehension task for students with and without attention problems. International Journal of Applied Educational Studies. 2012; I3(I): 19-32.

13. Bagatell N, Mirigliani G, Patterson C, Reyes Y, Test L. Effectiveness of therapy ball chairs on classroom participation in children with autism spectrum disorders. The American Journal of Occupational Therapy. 2010; 64(6): 895-903. https://dio.org/10.5014/ajot.2010.09149

14. Wu W, Wang C, Chen C, Lai C, Yang P, Guo L. Influence of therapy ball seats on attentional ability in children with attention deficit/ hyperactivity disorder. Journal of Physical Therapy Science. 2012; 24: $1177-1182$. https://doi.org//0.1589/jpts.24.1I 77

15. Ivory, D. The Impact of Dynamic Furniture on Classroom Performance: A Pilot Study. University of Puget Sound; 201 I. (Unpublished report).

16. Pfeiffer B, Henry A, Miller S, Witherell S. Effectiveness of disc 'O' sit cushions on attention to task in second-grade students with attention difficulties. The American Journal of Occupational Therapy [serial online]. 2008 [2013 Jun 28]; 62(3): 274-28I. https://dio.org/10.5014/ajot.62.3.274

17. Umeda C, Deitz J. Effects of therapy cushions on classroom behaviors of children with autism spectrum disorder. The American Journal of Occupational Therapy. 20 I I; 65(2): I52-I59. https://doi.org/10.5014/ajot.201 I.000760

18. Carrière B. The Swiss ball: Theory, basic exercises and clinical application. Ist ed. Berlin, Heidelberg: Springer-Verlag; 1998.

19. Lane S J, Schaaf R C. Examining the neuroscience evidence for sensory-driven neuroplasticity: implications for sensory-based occupational therapy for children and adolescents. The American Journal of Occupational Therapy. 2010; 64(3): 375-390. https://doi.org/10.5014/ajot.2010.09069

20. Zentall S S. Optimal stimulation as theoretical basis of hyperactivity. The American Journal of Orthopsychiatry. 1975; 45(4): 549-563. http://dio.org/10.1 III/j.1939-0025.1975.tb0 I I85.x.

21. Roley S S, Blanche E R, Schaaf R C. Understanding the nature of sensory integration with diverse populations. Ist ed. United States of America: Therapy Skill Builders; 200 I. ISBN-I3: 978-I4I6403326.

22. Zentall S S, Zentall T R. Optimal stimulation: A model of disordered activity and performance in normal and deviant children. Psychological Bulletin. 1983; 94(3): 446-47I. https://www.researchgate/ I 0.1037//0033-2909.94.3.446

23. Zentall S S, Shaw J. Effects of classroom noise on performance and activity of second-grade hyperactive and control children. Journal of Educational Psychology. 1980; 72(6): 830-840.

24. Abikoff H, Courtney M E, Szeibell PJ, Koplewicz HS. The effects of auditory stimulation on the arithmetic performance of children with ADHD and nondisabled children. Journal of Learning Disabilities. 1996; 29(3): 238-246. https://doi.org//0.1 I77/002221949602900302

25. Fedewa A L, Candelaria A, Erwin H E, Clark T P. Incorporating 
physical activity into the schools using a 3-tiered approach. Journal of School Health. 2013; 83(4): 290-297.

https://doi.org//0.1 I I I/josh. 12029

26. Mullender-Wijnsma M J, Hartman E, De Greeff J W, Bosker R J, Doolard S, Visscher C. Improving academic performance of schoolage children by physical activity in the classroom: I-year program evaluation. The Journal of School Health. 2005; 85(6): 365-37I. https://doi.org/10.1 I I I/josh. 12259

27. Webster C A, Russ L, Vazou S, Goh T L, Erwin H. Integrating movement in academic classrooms: understanding, applying and advancing the knowledge base. World Obesity. 2015; 16(8): 69I-70I. https://doi.org//0.1 I I I/obr. 12285

28. Kratochwill T, Hitchcock J, Horner R, Levin J, Odom S, Rindskopf D, Shadish W. Single Case Designs Technical Documentation. 20 I0; Accessed July 10, 2013. http://ies.ed.gov/ncee/wwc/pdf/wwc_scd.pdf

29. Schmidt M G, Rapp J T, Novotny M A, Lood E A. Detecting changes in non-simulated events using partial interval recording and momentary time sampling: evaluating false positives, false negatives, and trending. Behavioral Interventions. 20I2; 28(I): 58-8I. https://doi.org/10.1002/bin.1354

30. Tankersley M, Harjusola-Webb S, Landrum TJ. Using single subject research to establish the evidence base of special education. Intervention in School and Clinic. 2008; 44(2): 83-90. https://doi.org/10.1 I77/105345/208321600

3I. Cakiroglu O. Single subject research: applications to special education. British Journal of Special Education. 2012; 39(I): 21-29. https://doi.org/I0.1 I I I/j. I467-8578.2012.00530.x

32. Byiers BJ, Reichle J R, Symons FJ. Single-subject experimental design for evidence-based practice. American Journal of Speech-Language Pathology. 2012; 21 (4): 397-4I4.

https://doi.org/10.1044/1058-360(20 I 2/I I-0036

33. Sugai G, Rowe P. The effect of self-recording on out-of-seat behaviour of an EMR student. Education \& Training of the Mentally Retarded. 1984; February: 23-28.

34. Horner R, Carr E, Halle J, Mcgee GI, Odom SI, Wolery M. The use of single-subject research to identify evidence-based practice in special education. Exceptional Children. 2005; 7I(2): I65-I79. http://doi.org/I0.1 I77/001440290507100203

35. Education White Paper 6: Special needs education. Pretoria: Department of Education; 200I. ISBN: 0-7970-3923-6

\section{AUTHOR CONTRIBUTIONS}

Lise Reyneke is the first author and principal investigator. She completed the research as part of her Master of Occupational Therapy degree at Stellenbosch University.

Munira Hoosain is the second author and prepared the manuscript for publication.

\section{Corresponding Author}

\section{*Munira Hoosain}

Email: munira@sun.ac.za 